\title{
METÁFORA SINESTÉSICA EN EL QUIJOTE
}

1. En la metáfora sinestésica, ${ }^{1}$ la metáfora viene considerada como el translado de una esfera sensorial a otra. Si cada metáfora es una transposición de sentido de un término a un otro, basada en una comparación no expresada, la llamada sinestésica incluye dos esferas sensoriales distintas (voz cálida, lágrimas amargas). Es aceptado por todos los semantistas que una de las condiciones de la eficacia de la metáfora sinestésica, para algunos la más importante, es la distancia semántica entre los dos conceptos; al estar los dos conceptos demasiado cercanos o pertenecer a semejante campo nocional, la metáfora pierde vigor. Comparar dos seres o cosas (casi) idénticas, es posible; es, de alguna manera, una comparación pálida, inexpresiva. La metáfora sinestésica es eficaz, porque llega inesperadamente, sorprende, como postulaba el surrealismo francés (A. Breton). Si hoy día muchas metáforas sinestésicas no provocan ningun asombro, es debido a la suerte que toda metáfora sufre cuando llega a ser patrimonio lexical de una lengua.

El motivo de estas líneas es examinar si en Cervantes, más exactamente en El Quijote, hay un empleo abundante de este procedimiento semántico, ya que sabemos que durante el barroco, la generación poco posterior a la época cervantina hacía furores de todo lo que había podido ser el factor de sorpresa. Pero, sabemos también que el modelo del lenguaje cervantino es la discreción y las palabras "claras, llanas y significantes", como dijo el licenciado, camino de las bodas de Camacho. Cervantes observa, de manera realística, los acontecimientos y los narra con sencillez y genuinidad.

En El Quijote 2 se conoce poco el empleo del sintagma voz cálida, voz caliente; se conoce, claro, el adjetivo caliente, ya sea en el sentido primario, real, como en gustar algo caliente (I, 26), o en el sentido figurado a sangre caliente (II, 71). En las siguientes líneas, el análisis de algunos campos nocionales debería mostrar si el autor se sirve del procedimiento de transferir palabras de una esfera sensorial a otra.

2. El campo nocional de los colores es relativamente pobre. Aparecen verde, azul, amarillo, rubio, pardo, rucio, rojo, moreno y con esto el abanico de los colores del espectro solar está casi agotado. Encontramos, por supuesto, también blanco y negro. En general, los nombres de los colores o sirven para expresar el color real, como por ejemplo en II, 44 donde a don Quijote se le soltaron dos docenas de puntos de una media y por eso diera él por tener alli un adarme de seda verde una onza de plata; digo seda verde porque las medias eran verdes; o se trata del sentido figurado, ya consagrado del uso común. Para el adjetivo blan-

\footnotetext{
1 Stephen Ullmann, Semántica. Introducción a la ciencia del significado, Madrid, Aguilar, 1965. - Ullmann se sirve del término "sinestético". Aqui preferimos "sinestésico" para conservar conexión con "sinestesia".

2 Las citas son tomadas de Miguel de Cervantes, El ingenioso hidalgo Don Quijote de la Mancha, 33. a ed., Madrid, Espasa-Calpe, 1985.
} 
co podemos citar armas blancas, escudo blanco: habia de llevar armas blancas, como novel caballero (I, 2). Además, hay casos donde el adjetivo toma el valor de sustantivo, con el significado de centro: dio siempre muy lejos del blanco de la verdad (I, 33); tú eres [...] el blanco de sus deseos (I, 33); o de plata: respondióle don Quijote que no tenía blanca (I, 3); por negros que sean los he de volver blancos, o amarillos ('vender los esclavos negros a trueque de plata o de oro', I, 29). El elativo blanquísimo está siempre en el sentido original, material: Una piel blanquisima (I, 33); rimeros de pan blanquísimo (II, 20). Si encontramos negro en si al cabo de tanto tiempo volviera sin blanca y sin jumento a mi casa, negra ventura me esperaba (II, 4), no se trata de sinestesia: no están en juego las dos esferas sensoriales y no hay transposición de una esfera sensorial a otra; el término del color asume un sentido figurado, de lo concreto se pasa a una abstracción. A menudo estamos en presencia de lugares comunes, conocidos, empleados en la poesía: los manchegos, ricos y coronados de rubias espigas (I, 18); cabellos rubios como hebras de oro (II, 10). Igualmente, la metáfora el rubicondo Apolo, 'el Sol' el cual había tendido por la faz de la ancha y espaciosa tierra las doradas hebras de sus hermosos cabellos $(I, 2)$, hace parte del inventario poético de la época.

Podemos añadir que los adjetivos de los colores son utilizados debidamente en sentido real: al siempre vencedor y jamás vencido Timonel de Carcajona, príncipe de la Nueva Vizcaya, que viene armado con las armas partidas a cuarteles, azules, verdes, blancas y amarillas (I, 18).

Aparte del campo nocional del color hay adjetivos como amargo, agudo/acuto, blando, desesperado que efectivamente podrían formar parte del procedimiento sinestésico; de todos modos, el empleo en Cervantes no tiene nada de individual, se trata de lugares comunes: amarga adelfa $(\mathrm{I}, 13)$; de mi amargo pecho; Oh, amarga conversión $(\mathrm{I}, 14) ;$ en esta amarga soledad en que me dejas (II, 10); lo que me falta por contar lo amargo desta, hasta aquí dulce, historia (II, 39); con aquello tres angulos acutos (II, 38); lo tuvo por discreto y agudo (II, 18); con los ignorantes que presumen de agudos (II, 4); para conmigo no hay palabras blandas (I, 8); allá se inventó para los blandos cortesanos (I, 13).

3. Entre los sustantivos en un cierto sentido los predestinados a entrar en la esfera de la sinestesia hay que mencionar algunos, como fuego, llama. El primero se encuentra, sí, en su significado original: basta recordar la escena de la quema de los libros en la casa de don Quijote. En general, los dos sustantivos estan empleados en su significado de transposición: solo el fuego se acrecentó de manera que [yo] ardía de rabia, y de celos (I, 27); lanzando vivos los ojos [de cólera] (I, 46); Y fue esta negación añadir llama a llama, y deseo a deseo (I, 24); Del gran Quijote fue llama [Dulcinea] (I, 52). Para gusto, vocablo nacido en este sentido figurado en la corte española, no sorprende que Cervantes lo use siempre en el sentido translativo; aparece al principio de la novela: Puesto nombre, y tan a su gusto a su caballo (I, 1), y, además, en siempre nos da gusto el oir $(1,28)$; entre las damas había dos de gusto picaro, y burlonas (II, 62). Al contrario, el verbo gustar conserva su valor real, original.

El mundo de las flores no aparece con mucha frecuencia; encontramos mencionadas la margarita, la rosa, el jazmín y pocas otras. Faltan la amapola, el clavel, la azucena, aunque en épocas posteriores a Cervantes se emplearon abundantemente los nombres de las flores como metáforas. 
4. Hay además algunos verbos que llaman nuestra atención, como oir, ver, sentir, oler, pesar. Todos aparecen también en el sentido original: $y$ apenas las [voces] hubo oído (I, 4); siempre, Sancho, he oído decir (I, 23). Se considera también como un empleo en su sentido primario el verbo en II, 18: Paréceme que vuesa merced ha cursado las escuelas: ¿qué ciencias ha oído? Igualmente el verbo sentir: le preguntó que quién era y qué mal sentía (I, 5); Pero apenas llegó a la puerta, cuando don Quijote la sintió (I, 16); todos huelen a piedra azufre y a otros malos olores [...] si huelen, no pueden oler cosas buenas, sino malas y hidiondas (I, 47). Pero, es muy frecuente el uso en sentido translativo, lo que - otra vezno puede ser algo específico de la lengua cervantina, ni tampoco del español: a nuestro ver (II, 42); pero que tienen que ver los Panzas con los Quijotes (II, 60); por ser tan muchacha, no se sentia habil para poder llevar la carga del matrimonio (I, 12); no debe vuesa merced sentirse. -Si puedo sentirme o no, respondió don Quijote, yo me lo sé (II, 1); Mucho me pesa, Sancho (II, 2); cosa que me parece que huele algo a gentildad ${ }^{3}$ (I, 13); Vive Dios si os huele, que os mando mala ventura (II, 10 - soliloquio de Sancho).

5. Por todo lo visto anteriormente, deducimos que para Cervantes la función del narrador es la de escribir acontecimientos y no la de hacer descripciones. Sí, hay descripciones en su obra y en tal caso aparecen en número mayor los adjetivos. Un ejemplo célebre es la descripción de la beatitud de los siglos pasados donde en la dichosa edad y siglos dichosos aparecen las claras fuentes y corrientes ríos. En otro capítulo, (I, 23), aparece aurora pero el punto importante fue el hecho de que Sancho "halló menos su rucio". El Quijote es un texto épico; se presentan acciones y no situaciones. Podemos concluir con que Cervantes no se sirve de la sinestesia sino muy parcamente, y aun muchas veces con sintagmas que fueron desde mucho tiempo el material casi obligatorio de todo su quehacer poético.

Si el resultado de este pequeño examen es negativo, y lo es ya a la lectura superficial de la novela, hay un motivo para plantearse la pregunta sobre el empleo de la metáfora sinestésica en Cervantes y es que Shakespeare, su coetáneo, se burla de una manera cruel de tal procedimiento semántico, evidentemente muy en moda en la literatura inglesa de aquel período. Anota Ullmann el célebre paso I see a voice [...] hear my Thisby's face de A Midsummer Night's Dream. ${ }^{4}$ Como Cervantes se burla de modo sangriento de la moda, traída de Italia, sobre el empleo abundante del elativo en -ísimo, y la escena de la dolorosísima dueñísima nos ofrece una prueba evidente, se hubiera burlado igualmente del abuso de la metáfora sinestésica en el caso de haber esta formado parte de la moda literaria de la época.

3 Herejia, porque, según Vivaldo $(I, 13)$, los caballeros andantes antes de una aventura se encomiendan a sus damas y no a Dios.

4 Ullmann, cit., pág. 245. 


\section{SINESTEZIČNA METAFORA V DON KIHOTU}

Metafora je raba neke besede namesto kake druge zaradi kake skupne črte. Pri sinestezični metafori sta udeleženi dve čutni sferi; iz estetike francoskega surrealizma je znano, da je metafora (v globini vendarle 'primera') toliko bolj močna, kolikor sta si ti dve čutni sferi oddaljeni. Cervantesov jezik ima v Don Kihotu sinestezičnih metafor malo, najbrž tudi zato, ker je opisov razmeroma malo. Bohotna doba sinestezične metafore je imela nastopiti šele $v$ poznem španskem baroku. 